\title{
Erratum to: Parental Anxiety and Child Symptomatology: An Examination of Additive and Interactive Effects of Parent Psychopathology
}

\author{
Marcy Burstein • Golda S. Ginsburg • Jenn-Yun Tein
}

Published online: 10 September 2010

(C) Springer Science+Business Media, LLC 2010

\section{Erratum to: J Abnorm Child Psychol}

DOI 10.1007/s10802-010-9415-0

1) The title in the published article contains a typographical error. The title of the article should read: Parental Anxiety and Child Symptomatology: An Examination of Additive and Interactive Effects of Parent Psychopathology

2) The authors wish to include the following acknowledgment:

This research was supported by National Institute of Mental Health grants T32MH020033 awarded to Dr. Mark Riddle and K23MH6342702 awarded to Dr. Golda Ginsburg at the Division of Child and Adolescent Psychiatry, Johns Hopkins University School of Medicine.

The online version of the original article can be found at http://dx.doi. org/10.1007/s10802-010-9415-0.

M. Burstein · G. S. Ginsburg

Division of Child and Adolescent Psychiatry,

Johns Hopkins University School of Medicine,

Baltimore, MD 21287-3325, USA

J.-Y. Tein

Prevention Research Center, Arizona State University,

Psychology North,

Tempe, AZ 85287-6005, USA

Present Address:

M. Burstein $(\bowtie)$

Section on Developmental Genetic Epidemiology,

National Institute of Mental Health,

35 Convent Drive, Building 35, Room 1A104 (MSC 3720),

Bethesda, MD 20814, USA

e-mail: bursteinme@mail.nih.gov 